\title{
Trainee Teachers with Dyslexia: Results of a Qualitative Study of Teachers and their Mentors
}

\author{
Jonathan Glazzard \\ Leeds Beckett University \\ Leeds, United Kingdom
}

\begin{abstract}
This study explored the perceptions of trainee teachers with dyslexia, and their mentors, of their placement experiences during their initial teacher training course. The research was conducted within one initial teacher education partnership in the north of England. Data were collected through two focus groups; one of trainees and one of mentors. Trainees described the difficulties they experienced with teaching literacy (particularly phonics), difficulties with memory and difficulties with the administrative demands of placement. Mentors emphasised trainees' weaknesses and although some mentors wanted to recognise and support the strengths of the trainees, they felt responsible as gatekeepers to the profession.
\end{abstract}

Keywords: Dyslexia; Literacy; Initial teacher training; Placements.

\subsection{Introduction and Literature Review}

\subsection{Focus of the study}

All initial teacher training courses must provide trainees with structured, supervised time in schools in order to develop the practical skills of teaching. This is referred to as 'placement'. This qualitative study examines the perceptions of a group of trainee teachers with dyslexia of their experiences of school placements. Additionally, the study examines the perspectives of a group of mentors who had experience of mentoring trainees with dyslexia. The term 'mentor' is used to refer to teachers who work in placement schools and who assume responsibility for the direct supervision of trainee teachers during placement. Data were collected from participants representing one initial teacher education partnership in the north of England. The university provider, its trainees and mentors from partnership schools represent the 'partnership'. The author of this study, at the time of collecting the data, was programme leader for all primary education initial teacher training courses in this partnership. 


\subsection{Context}

The Equality Act (HMSO, 2010) places a legal responsibility on higher education providers to ensure equality of opportunity for students with recognised disabilities by removing barriers to participation and achievement. Universities need to ensure that students with disabilities have not been subjected to direct or indirect discrimination and have had equality of opportunity to achieve their potential.

However, competing policies result in the marginalisation of people with disabilities. Professions such as teaching, nursing and social work are subject to fitness to practice regulations and teacher training providers have a responsibility to ensure that all trainees meet the minimum expectations as set out in the teachers' standards (DfE, 2011). Thus, providers face the challenge of meeting the individual needs of trainees with disabilities at the same time as maintaining the integrity of their teacher training programmes. Additionally, the introduction of a more rigorous National Curriculum (DfE, 2013) in schools has meant that primary teacher training providers must now ensure that all trainees are able to demonstrate higher standards of literacy than was previously the case.

The focus on raising standards in schools has resulted in a political focus on the quality of initial teacher training courses. Inspection frameworks for initial teacher training have become increasingly rigorous over the past decade with a sharper focus on how effectively trainees teach subjects, for example, literacy. This can present trainees with disabilities with significant challenges if they experience barriers to learning in specific areas of the curriculum. In order for providers of initial teacher training to demonstrate that they are compliant with the Equality Act, they need to be able to demonstrate that reasonable adjustments have been provided for trainees with disabilities. The implementation of reasonable adjustments aims to ensure that barriers to achievement are removed, thus enabling equality of opportunity. This reflects the principles of the social model of disability.

\subsection{Students with dyslexia in higher education}

Research on the experiences of students with dyslexia during their higher education suggests that academic staff lack knowledge or understanding of dyslexia or have not been trained to support students' needs (Hanafin et al., 2007; Mortimore \& Crozier, 2009; Riddell \& Weedon, 2006). Students with dyslexia have reported unsympathetic attitudes from lecturers (Madriaga, 2007) and lack of flexibility in the way they are assessed through an over-emphasis on written assessments (Fuller et al., 2004). Riddell and Weedon (2006) found that academic staff were sceptical about dyslexia and did not consistently agree with making reasonable adjustments. More recent research indicates that the quality and quantity of support and reasonable adjustments to students with dyslexia in higher education is inconsistent (Fuller et al. 2009; Pavey et al., 2010) and amounts to little more than a 'lottery' (Griffiths, 2012). All of these studies are qualitative and involve small numbers of participants, thus reducing their reliability. 


\subsection{Challenges for trainee teachers with dyslexia}

Dyslexia is classified as a disability under the Equality Act (HMSO, 2010). Despite the introduction of the Equality Act trainee teachers with dyslexia still fear discrimination and this results in a reluctance to declare their disability (Griffiths, 2012). There is an expectation that all trainee teachers are able to demonstrate high standards in literacy in order to safeguard standards in schools. Consequently, trainees with dyslexia are often viewed as a threat to standards rather than a valuable resource to the teaching profession (Ferri et al, 2001; Griffiths, 2012; Riddick \& English, 2006).

The requirement for teachers to demonstrate high standards of literacy has been seen as central to raising standards of literacy in schools and this raises questions about the suitability of those with dyslexia as teachers (Riddick, 2003; Riddick \& English, 2006). Implicit within this is the assumption that trainees with dyslexia are not able to teach reading and writing skills to a sufficiently high standard.

Research has indicated that trainees with dyslexia are viewed as a burden in that they may require additional support and may threaten the standards which schools aspire to achieve (Griffiths, 2012). Riddick and English (2006) have questioned the focus on standards by asking:

Do teachers' own standards impact on the literacy standards of the children they are teaching? ... How many children have left school unhappy (or poorly educated for that matter) because their teacher misspelled the odd word?

(p. 206)

The focus on literacy standards in schools presents trainees with dyslexia with a significant barrier and diverts attention away from curriculum areas or other attributes which may be significant strengths. Additionally, the political focus on teaching children to read through synthetic phonics (DfE, 2010; DfE, 2016; Rose 2006) has resulted in the development of inspection frameworks for schools and initial teacher training providers which emphasise this aspect of the curriculum above others. For the past decade inspections of schools and initial teacher training have focused on how effectively teachers and trainees teach phonics and for trainees and teachers with dyslexia this is a skill which does not develop automatically. This is because dyslexia arises from a phonological deficit affecting the processing of speech sounds in words (Snowling, 1995; 1998; Snowling, 2013). Trainees who are placed with children aged 5-6 years are likely to find that a significant proportion of curriculum time is invested into preparing children for the phonics screening check and for trainees with dyslexia this presents them with an additional barrier in comparison to other trainees who may develop phonics knowledge and skills with greater automaticity.

\subsection{Placement experiences of trainee teachers with dyslexia}

Although there is some research on the effect of dyslexia on pupils' self-esteem (Glazzard, 2010; Humphrey, 2002; Humphrey \& Mullins, 2002b), there is a paucity of research on the experiences of trainee teachers with dyslexia during their initial teacher training course, specifically in relation to placements. Evidence suggests that training experiences, particularly experiences of placements, can impact on trainees' self-esteem (Hobson \& Malderez, 2013). 
Whilst there is some literature on teachers' experiences of dyslexia (Burns \& Bell, 2010; 2011), only one study has been located which specifically discusses the experiences of trainee teachers with dyslexia of their initial teacher training placements (Griffiths, 2012). This was a small-scale study in which data were collected from six student teachers in one higher education institution. No information has been provided on how these participants were selected and the sample size was small. These factors reduce the reliability of the study. Additionally, the study did not explore mentor perceptions and therefore lacked triangulation. This reduces the validity of the research. The literature which does exist focuses more on the selection process onto initial teacher training courses in relation to those with dyslexia (Riddick \& English, 2006) or the general experiences of trainee teachers with dyslexia of their university courses (Cameron \& Nunkoosing, 2012; Morgan \& Burn, 2000). Consequently, little is known about the challenges that trainees with dyslexia face on placement and how they overcome these.

Furthermore, research has found that the transfer of support from the university to school placements for trainee teachers with dyslexia is variable (Griffiths et al. 2010). Whilst many universities now have central departments which are responsible for assessing students' needs and determining reasonable adjustments for students on campus, insufficient consideration is often given to planning reasonable adjustments for students on placement (Griffiths et al., 2010; Griffiths, 2012). The cognitive impairments associated with dyslexia may have detrimental effects upon attainment in reading, writing, numeracy, oral fluency, organisation, attention and self-esteem (Pavey et al., 2010; Pollak, 2009) but the profile of impairments is unique to each individual. Reasonable adjustments needed to help students achieve on placement may be different to those adjustments which are provided to students on campus and careful planning is required to ensure that the correct adjustments are put in place when students undertake a placement. One study concluded that placements and mentors are often not carefully matched to individual students' needs resulting in impaired confidence and self-esteem and stress (Timmerman, 2009). This was a small-scale study in which data were collected from 13 teacher-educators. The validity of this claim could have been strengthened had the perspectives of student teachers been explored in addition to the perspectives of the teachereducators.

As a result of the challenges which have been highlighted, trainees with dyslexia fear being misunderstood, stigmatised, labelled and misjudged because colleagues in school lack awareness of dyslexia (Beverton et al., 2008; Pollak, 2009). Research has indicated that students with dyslexia may not perceive any tangible benefits of disclosing their disability to their placement setting (Morris \& Turnbull, 2007) and disclosure to the mentor has been considered high risk (Griffiths, 2012). The focus on high performance results in their unique strengths being ignored and their differences being undervalued (Onken \& Slaten, 2000).

\subsection{Strengths of trainees with dyslexia}

Trainees with dyslexia have many strengths which they can bring to the teaching profession (Duquette, 2000; Riddick, 2000; 2001; 2003). Research has 
indicated that trainees with dyslexia feel that they unique insights into the difficulties experienced by the children they are teaching (Glazzard \& Dale, 2013; Griffiths, 2012). Burns and Bell (2010) found that trainees with dyslexia demonstrated empathy and sensitivity towards children with disabilities as a result of their own experiences of educational exclusion. Often, they developed their own compensatory coping strategies to make their professional lives easier (Burns \& Bell, 2010), such as purchasing technological aids to help them with spelling. Other research has demonstrated how trainees with dyslexia were particularly skilled at developing highly effective relationships with pupils with behavioural difficulties (Burns \& Bell, 2011). Griffiths (2012) found that trainees with dyslexia had strengths in curriculum areas such as art, drama and physical education and were able to develop skills such as differentiating the curriculum for children with special educational needs and disabilities more automatically than trainees without dyslexia.

\subsection{Strategies for supporting trainees with dyslexia}

The ICF model provides a useful framework for understanding the impact of dyslexia on an individual's ability to perform a task or participate in a life situation. In relation to trainee teachers with dyslexia, impaired bodily functions (i.e. difficulties with phonological processing) can affect specific activities such as reading and writing. This can affect a trainee's ability to participate in teaching these aspect of the curriculum. Environmental factors (i.e. the attitudes of mentors and provision of reasonable adjustments) can alleviate or exacerbate the difficulties which are experienced and personal factors, such as self-concept and self-esteem must also be taken into account.

The literature makes clear recommendations for ways in which schools and universities can more effectively support the needs of trainee teachers with dyslexia. Examples of recommendations from Griffiths (2012) include: proactively planning placement support; placing the student at the centre of the planning process; applying a model of placement support which is flexible and responsive to trainees' individual needs; pairing trainees with dyslexia with dyslexic mentors and developing alternative ways of presenting portfolio evidence. Whilst these recommendations are important and will potentially improve trainees' placement experiences, there is insufficient consideration given to the type of support that may be required to enable trainees with dyslexia to develop their knowledge and confidence in relation to teaching phonics on placement. Given that the core deficit in dyslexics appears to be phonological processing (Snowling, 2013) and the political emphasis on phonics, it seems logical to suggest that universities and schools should further consider what support may be required in this area before, during and after placements.

\subsection{Theoretical framework}

Building on the medical and social models of disability this study is framed within the bio-psycho-social model of disability. The World Health Organization released the bio-psycho-social model for disability, the International Classification of Functioning, disability and health (ICF) (WHO, 2001), which aims to provide a holistic definition of health by essentially merging the medical and social models. The model recognises the complex inter-relationships 
between biological and contextual factors which influence how disability is experienced by the individual. These are identified below:

Body functions and structures: the body functions and structures of people; problems with the integrity of structures or their functions are termed impairments (functioning at the level of the body).

Activity: the activities/tasks people undertake; difficulties undertaking those are termed activity limitations (functioning at the level of the individual).

Participation: the participation/involvement of people in life situations; difficulties are termed participation restrictions (functioning of a person as a member of society).

Environmental factors: the external factors (physical, social and attitudinal) which affect people's experiences (and whether these factors are facilitators or barriers). Personal factors: these are the internal factors which affect people's experiences (and whether these factors are facilitators or barriers).

(WHO, 2001)

The ICF was created to define/describe health, but recognizes that a breakdown/problem with any of the components can affect health experiences. For instance, an impairment of a body function may exist, but the impact of that is only seen when we consider how it affects an individual's ability to perform a task or participate in a life situation, and that the degree to which that participation is affected is moderated by contextual factors (personal and environmental) that acts as barriers/facilitators.

Often the models of disability are represented as though they are distinct and the critical literature on the medical model (Thomas \& Loxley, 2001; 2007) underplays the role that a person's biological impairments can play in restricting access to goods and services. However, the implementation of interventions which address biological and contextual factors can potentially have a greater impact than operating within the principles of one model in isolation to the others.

\subsection{Research aims and questions}

Trainees with dyslexia have much to offer as students and future teachers, but require support in order to develop their skills. Universities have an obligation to support trainees, but it is unclear whether this is happening in the most effective way. One of the key reasons is that trainees undertake significant learning away from universities; when on placement. Yet the beliefs and skills of mentors who support trainees with dyslexia on placement is not known and their need for further training and capacity-building to support these students is also unclear. This study explored the following research aims:

- What were the collective experiences and perceptions of dyslexic trainee teachers of their initial teacher training placements?

- What were the collective experiences and perceptions of mentors in relation to trainee teachers with dyslexia?

- What benefits do trainees with dyslexia bring to the teaching profession and what are challenges are associated with being a teacher with dyslexia? 


\subsection{Methodology and Methods}

Given that the aims of the study focused on eliciting the perceptions of mentors and trainees a qualitative, interpretive approach was deemed to be suitable. Two focus groups were conducted; one with trainees and one with mentors.

Each group comprised six participants. Each participant in the mentor focus group was female. Each mentor had been mentoring trainees for ten years or more. Two of the mentors had mentored four trainees with dyslexia, three had mentored two trainees with dyslexia and one mentor had mentored one trainee with dyslexia. All mentors had experience of mentoring a trainee with dyslexia within the last two years. In the trainee focus group there was an uneven split of males and females (males $n=2$; females $n=4$ ). All trainees were in their second year of an undergraduate degree in primary education and had completed two six-week placements in a primary school prior to their participation in this study. The trainee sample was a purposive sample and consequently 'it does not pretend to represent the wider population; it is deliberately and unashamedly selective and biased' (Cohen et al., 2011, p.104). All of the trainee participants volunteered to be part of the study because each of them had negative experiences of placements that they wished to share. The mentor sample was purposive in that it only included teachers who had experience of mentoring trainees with dyslexia. Both focus groups were digitally recorded to reduce the potential for data loss which happens when researchers only take notes from interviews. Data were later transcribed and analysed using Interpretive Phenomenological Analysis (IPA) (Smith et al., 1997).

\subsection{Results}

\subsection{Overview of results}

The themes that emerged from the transcripts focused difficulties trainees experienced with literacy, specifically in relation to teaching phonics and writing. Trainees also identified difficulties with memory and managing the administrative requirements of placement. Mentors concurred with many of these difficulties. Additionally, trainees associated criticism from mentors as discrimination. Trainees highlighted specific strengths in their teaching which they attributed to their personal experiences of dyslexia. In the following sections, each theme will be discussed with excerpts from the focus groups used to illustrate the experiences of the trainees and mentors.

Data analysis revealed that all trainee participants had experienced challenges whilst on placement, particularly in relation to the teaching of early reading, spelling, grammar and punctuation. Detailed analysis indicated each individual had unique experiences, but all identified challenging situations, caused by their condition, the requirements of their role and the context in which they worked. This included the attitudes and support of their mentors. The challenges which they experienced reflected the interaction between the medical and social models of disability. Some trainees were scared about the prospect of not passing, some were disappointed about the perceived lack of support they received and others questioned whether to continue. Mentors confirmed some of these challenges but also expressed concerns about the impact that trainees' literacy difficulties had on children's development and progress, thus 
illustrating the complex nature of the issues. Part of the complexity arises from the fact that the mentors created the environment in which the trainees worked and which impacted on the degree of disability they experienced. However, the mentors also existed within an environment which impacted on them. They were influenced by the curriculum standards and the expectations of their stakeholders, to which they were accountable.

Pseudonyms have been used throughout this section as shown below:

Table 1: Names of participants

\begin{tabular}{|c|c|}
\hline Trainees & Mentors \\
\hline Sally & Dorothy \\
\hline Kate & Shirley \\
\hline James & Fran \\
\hline Tom & Jane \\
\hline Alice & Sarah \\
\hline Ayesha & Susan \\
\hline
\end{tabular}

\subsection{Literacy difficulties}

All trainee participants experienced difficulties with teaching literacy and these difficulties were categorised into either 'difficulties with teaching phonics' or 'difficulties with teaching writing'. Mentors confirmed that these specific difficulties were problematic in the context of a standards agenda in schools.

\subsubsection{Difficulties with teaching phonics}

Although all trainee participants acknowledged their difficulties with phonics individual participants emphasised different issues in relation to this theme. Whilst Tom focused on the limitations of his own subject knowledge, Alice and Sally emphasised the criticism that they had encountered by their mentors. Kate emphasised the anxiety that she experienced prior to an assessment of her teaching capability:

'I find it difficult to hear the sounds in words. I know that a word like 'dog' has three sounds (d-o-g) but when I have to break down a more complex word like 'cornflakes' I find it difficult to identify the units of sound.' (Tom).

'My mentor criticised my phonics teaching because I could not identify and address children's misconceptions.' (Alice).

'I just can't seem to grasp the complex alphabetic code and my mentor became very frustrated with me because I kept needing to ask for her support when planning lessons' (Sally).

'Every time I taught phonics I was nervous. I was terrified that I would make a mistake.' (Kate).

Mentors all expressed concerns about the difficulties that trainees with dyslexia experience when teaching phonics. However, individual mentors acknowledged different issues in relation to this. Whilst most mentors focused on the detrimental impact on pupils' learning (Sarah, Jane), Jane also emphasised that she felt torn between supporting her trainee and ensuring that her pupils 
achieved highly. Some mentors resented the increase in workload that was created by providing trainees with dyslexia with additional support (Sarah). 'I resent providing additional support to those trainees. My energies need to be directed towards supporting my pupils.' (Sarah).

I had a trainee with dyslexia who taught brilliant, creative lessons. Her lessons were fun and exciting and when she was teaching phonics she focused on planning interesting activities which engaged the children...I had to pull her up on her subject knowledge and I felt terrible for doing this when she had worked so hard in planning interesting lessons. But at the end of the day the children are tested and if they are not taught correctly they will not pass' (Jane).

Dorothy commented that her trainee experienced difficulties in teaching phonics but that he had also interpreted any criticism of his teaching as a form of discrimination. Fran also failed two trainees with dyslexia because they were 'not able to teach phonics'. Shirley prevented her trainee from teaching phonics because the trainee's subject knowledge was weak. Sarah, Jane and Shirley all emphasised their commitment towards their pupils achieving highly. Susan highlighted how she had to provide additional support to enable her trainee to plan phonics lessons.

\subsubsection{Difficulties with teaching writing}

All participants reported difficulties with spelling. However, individual participants emphasised different issues arising from difficulties with writing. Some participants reported difficulties with memorising grammatical rules and the rules of punctuation (Tom, Alice). Two trainees emphasised a lack of confidence in relation to teaching as a chosen profession as a result of their difficulties with writing (James, Tom). Some trainees emphasised mentor criticism arising from their writing difficulties (James, Tom). One trainee reported that her difficulties with spelling were exacerbated when she felt under pressure (James). Some trainees questioned the value of teaching grammar and punctuation through tasks which are decontextualized (Tom, Alice):

'I hate writing on the board because I am terrified that I will make a spelling mistake. I try to avoid it as much as possible. I dread shared writing lessons where I have to model the writing process. I once modelled some writing using the computer but my mentor pulled me up for that because she said I wasn't modelling letter formation. It made me question whether I should be going into teaching" (James).

'We now have to teach so much spelling, grammar and punctuation and the children are tested on it in Year 2 and Year 6. I find all of this very difficult and it makes me nervous when I have to teach it. I want children to enjoy writing. I am good at developing creative ideas which hook children into writing but my mentor said there was no substance to it because I was not teaching children the skills they needed to become better writers. After she said that I thought- I'm crap, I should not be teaching' (Tom).

'I find the rules about grammar and punctuation difficult because I wasn't taught those rules at school and I can't see the point of asking children to underline a noun, verb or adjective in a sentence. How does this make them better writers?' (Alice).

All mentors expressed considerable concern in relation to the teaching of writing but individual mentors emphasised different issues. Some mentors emphasised the importance of teachers being accountable to children, parents and official agencies such as the Office for Standards in Education (Ofsted). Dorothy's feedback to her trainee was interpreted by her trainee as 'discrimination' rather 
than constructive help. One mentor emphasised the tension between supporting the needs of the trainee at the same time as being a teacher of children (Susan). Another mentor focused on how her trainee could support the weaker writers very effectively but was less effective at challenging the more-able writers (Fran). Most mentors emphasised the difficulties that trainees had with spelling: 'I had a trainee with dyslexia who kept making spelling mistakes on the board. I had to intervene and I felt terrible for doing so. Yes, they were upset, but surely it is more important to make sure the children are taught correctly. I am a teacher first and a mentor second' (Susan).

'He [trainee] kept making spelling mistakes in the children's books and on the children's reading records. How do I explain that to parents and to Ofsted?' (Sarah).

'She sent home a list of spellings with words which were incorrectly spelt. How embarrassing! The parents came into school and complained I had to speak to her [trainee] and she responded by saying I was discriminating against her because she had dyslexia.' (Dorothy).

'I had a trainee with dyslexia who was very good at supporting the weak writers. She was able to address the needs of these pupils quite well. However, she was hopeless at stretching the more able writers because she did not grasp the skills herself' (Fran).

\subsection{Difficulties with memory}

All trainee participants reported having difficulties with working memory, specifically in relation to literacy. However, memory difficulties resulted in different problems for individuals. Some participants emphasised difficulties with memorising phonemes (Sally), others focused on grammar, spelling and punctuation rules (Kate) and one trainee reported difficulties in memorising letter joins in handwriting:

'I could not remember the phonemes and their corresponding graphemes. This was more difficult for me because I have a poor memory because of my dyslexia but I was teaching the complex code and I just could not remember all the different variations' (Sally).

'I am hopeless at remembering spelling rules. I find spelling difficult anyway and I learn spellings by visualising the whole word. The rules for spelling in English are so inconsistent that I just cannot remember them all' (Kate).

'I could not remember all the different things I had to do outside my teaching. I forgot to do record keeping. Writing lesson evaluations was just too much effort. I wanted to do it all electronically but my mentor said everything had to be in a ring binder and available to see' (Kate).

Mentors emphasised difficulties with working memory but tended to emphasise non-subject specific issues. Individual mentors focused on different issues that related to the category of 'difficulties with memory'. Some mentors emphasised how problems with memory resulted in problems with personal organisation (Sarah) whilst others emphasised ways in which memory difficulties impacted detrimentally on their teaching (Susan). There was no mention by trainees or mentors of additional support from mentors to help trainees retain important information.

'I told him every day what the class routines were and he still mixed them all up. One day I was completely exasperated and I said to him - 'how many times do you need to be told?' I mean, routines are important for young children' (Susan). 
'He would forget his resources and his lesson plans. I started to question whether he had really planned his lessons at all. I told him loads of really important stuff about each child that he needed to know but he just forgot everything' (Sarah).

\subsection{Administrative difficulties}

All trainee participants reported difficulties with paper work. The nature of the difficulties varied but all related to the general administrative duties that teachers are required to complete in their day-to-day work. Although trainees provided insights into the views of mentors in relation to these difficulties, this was not an issue that mentors addressed in the focus group:

'My teaching file was a total mess and my tutor criticised it. It was so disorganised that she could not track through it and get a sense of my development. She told me to improve it between her visits' (Ayesha).

'I hate filling in lesson plan forms. My mentor told me that my lesson plans were not good enough. I could not remember what to put in all the boxes'. (Tom).

'I just could not organise myself to get everything done. My mentor had a massive go at me because I had not completed some assessments of the children' (Sally).

Although the issues raised by participants all related to administration, individual participants emphasised different aspects of administration. Whilst some trainees focused on the organisation and presentation of files (Ayesha), others emphasised difficulties with understanding how to complete the required paperwork which they needed to do to pass the placement (Tom). Some trainees focused on the criticism of their paperwork by tutors and mentors (Ayesha, Tom, Sally) and others questioned the value of the documentation in the files and the value of other general administrative tasks that had been assigned to them. One trainee had suggested an adaptation to help with the burden of administration but this was not accepted by her mentor. There was no mention of any specific support or adjustments which might have been provided to make the administration easier.

\subsection{Criticism and 'discrimination'}

Most trainees highlighted different ways in which they felt they had experienced discrimination. The nature of the perceived discrimination varied across the participants but all implied that the initial teacher training partnership had not fulfilled its obligation to make reasonable adjustments under the Equality Act. Trainees mentioned specific adjustments which would have been beneficial to them, yet were not provided:

'I hated it. My mentor was totally unsupportive. It has damaged my confidence. They wouldn't do that to kids. No-one asked me before the placement started what help I needed to help me to complete the placement successfully. I passed but I could have passed with a much higher grade if some simple adjustments had been made. If I had been allowed to set out my lesson plans as mind maps that would have helped me for example' (Tom)

'There was no joint meeting with my, my link tutor and mentor prior to the placement starting. This would have been helpful in that it would have given me an opportunity to explain my specific needs' (Kate).

'I had to buy a spell-checker but I feel this should have been provided' (Ayesha).

'I asked if I could verbally record my lesson planning and evaluations on a Dictaphone and my mentor said this was not allowed. If I had been allowed to do this I could have 
concentrated on providing children with exciting lessons. The paper work took me so long to complete that it definitively impacted on my teaching. Being constantly criticised for my teaching of literacy was demotivating and I nearly gave up. She discriminated against me.' (James).

'I took so much criticism that now I have broad shoulders. It just bounces off me. Yes, I feel it was discrimination.' (Sally).

Some trainees emphasised the issue of mentor criticism and where this was discussed it was associated by the participants as a form of discrimination (Sally, James). Whilst it is possible that criticism could constitute discrimination, it is important to emphasise that criticism of performance is not in itself discriminatory but perhaps reflects a lack of understanding by the mentors on how to effectively support a trainee with dyslexia. This could be due to inadequate mentor training. It could also reflect the pressure on mentors to maintain high standards of pupil achievement. These themes were identified by the mentors:

'I felt inadequately prepared for my role in supporting a trainee with dyslexia. The university did not cover this in mentor training' (Jane).

'I was so worried that my pupils would not make the expected rate of progress that half term when my trainee was in. I criticised his teaching but it was because the Head is breathing down my neck to get the results up'. (Shirley)

\subsection{Strengths}

All trainee participants were able to identify ways in which their dyslexia impacted positively on their teaching. Individual participants emphasised different strengths. Some focused on how their experiences of dyslexia had made them more empathic towards children who have learning difficulties (Kate, Sally, Alice). Others emphasised how their own learning difficulties had enabled them to automatically differentiate tasks for less-able learners and support them in overcoming barriers to learning (Kate). Some trainees emphasised their skills in teaching creative subjects (James, Tom), whilst others emphasised their ability to think laterally (James):

'I love working with the children who struggle with literacy. I find it easy to differentiate the tasks for them. I understand the difficulties they have because I have also experienced the same difficulties.' (Kate).

'I am more caring, particularly towards children who find learning difficult. I love working with children with special educational needs.' (Sally).

'I am a more creative teacher because of my dyslexia. I am a creative person and I am able to think outside the box.' (James).

'I have my weaknesses but I am a creative teacher. I love teaching subjects such as art and drama and this is what has kept me on the course.'(Tom).

'The amount of criticism of my teaching made me question - 'do I really want to teach if teaching is like this?'. But in another way it has made me more determined to help kids with difficulties. I know I'm good at that. I think I will go into special needs.' (Ayesha). 'If children don't understand something I am able to show them other ways of approaching it. I love working with children with special needs and I think having dyslexia makes me more caring towards them' (Alice).

The mentor participants highlighted the strengths of trainees with dyslexia but often commented on corresponding weakness at the same time: 
'My trainee was creative and he was able to excite the children through drama. But at the end of the day he could not teach literacy and children are tested in that, not in drama' (Jane)

'Yes, she was brilliant with children with special needs but she could not stretch the more-able ones and that is a skill that is identified in the teachers' standards' (Fran).

'It's all well and good being able to teach art, which she did very well, but she could not teach phonics and I have to balance this against the expectations of the Year 1 phonics screening test' (Sarah).

'It is no good being able to teach children with special needs. He was brilliant with this group. However, these children will not make any difference to our results. If he is going to survive as a teacher he needs to be able to push the top end' (Shirley).

\subsection{Discussion}

Although the findings are grouped into broad themes individual participants emphasised different experiences in relation to each theme. Thus, rather than generating collective experiences it must be recognised that the experiences of individual mentors and trainees are unique.

The findings were largely consistent with previous research in that all trainee participants reported literacy difficulties, particularly in relation to spelling, grammar and punctuation (Griffiths, 2012). These difficulties varied across individuals but included gaps in their own subject knowledge and problems with memorising rules. Trainee participants also reported difficulties with memory and administration. Trainees felt unsupported by their mentors in addressing their difficulties with literacy, memory and administration. These difficulties are consistent with previous research and are well-documented in the literature (Griffiths, 2012; Hatcher et al., 2002; Mcloughlin et al., 2002; Mortimore \& Crozier, 2009; Pollak, 2009).

An emergent theme in the data specifically related to difficulties with phonics. This specific difficulty was also confirmed by the mentor participants. Trainees reported limitations in their own phonic knowledge and difficulties in the teaching of phonics. This specific issue had not been identified in previous research on trainee teachers' experiences (Burns \& Bell, 2010; 2011; Griffiths, 2012; Morgan \& Burns, 2000). It is perhaps unsurprising that trainees reported difficulties in phonics given the research on causation which indicates that dyslexia is caused by difficulties in phonological processing (Carroll \& Snowling, 2004; Velluntino et al., 2004; Snowling \& Hulme, 2012). However, irrespective of these difficulties, the teaching of phonics in primary schools is 'high-stakes' following the introduction of the phonics screening check in Year 1 and revisions to school and initial teacher education inspection frameworks over the past decade. In view of this wider policy context, supporting all teachers to develop good subject and pedagogical knowledge in this curriculum area must be a priority for every initial teacher education partnership.

There is a clear need for initial teacher training partnerships to consider carefully how they support trainees with dyslexia both to develop good phonemic and pedagogical knowledge so that they are able to teach phonics effectively. Whilst there is a paucity of literature on how trainee teachers with dyslexia can be better supported to teach phonics, there is literature on how children and young people with dyslexia can be better supported in learning to read (Rose, 2009). It 
is possible to draw out of this research aspects of effective practice which could be used to support trainee teachers with dyslexia in higher education.

According to Barber and Mourshed (2007, p.6) 'the quality of an education system cannot exceed the quality of its teachers'. Initial teacher training partnerships therefore need to consider what types of interventions will best support the needs of student teachers with dyslexia to teach phonics more effectively. Brooks (2007) highlighted the need for intensive interventions for children and young people with dyslexia and this may also be appropriate for trainee teachers in higher education. In relation to supporting children and young people with dyslexia, it is considered to be good practice to provide a multisensory, structured, daily programme of phonics which provides opportunities for consolidation and reinforcement (Rose, 2009). Trainee teachers with dyslexia may also benefit from exactly this type of intervention through which they can gradually develop their phonic knowledge through a process which provides them with opportunities to revisit prior learning. Intensive oneto-one tuition (Rose, 2009) may also benefit trainees in addition to the phonic training which they receive as part of their regular training. Regular on-going assessment of trainees' phonic knowledge and skills is critical to effective progress, as is the case when planning interventions for children and young people (Rose, 2009). In addition, trainees' progress should be regularly monitored during the intervention and teaching should be flexibly adapted in response to misconceptions. Explicit training in the skills of phoneme addition, phoneme deletion, phoneme substitution, blending and segmenting will also help trainees to systematically develop the skills they will be required to teach in schools.

The need to place trainee teachers at the centre of any intervention is critical to ensure that they have ownership of their training. Initial teacher education partnerships will need to decide which interventions are implemented by specific partners. It is perhaps more appropriate for the university to take ownership of the systematic intervention which is carefully designed to develop trainees' phonological skills. Trainees might benefit also from timely intervention prior to a placement to revise some of the knowledge and skills they have developed during the intervention. This could be delivered by the university. The university intervention programme could then be supplemented by a well-planned programme of school-based intervention which takes place during placements. Again, trainees should be involved in planning such interventions. Examples of school-based interventions could include coaching by an expert mentor who is skilled in teaching phonics. The trainee participants in this study were left 'floundering' on placement and might have benefitted from joint planning, team teaching and guided observations of phonics lessons by expert teachers.

Bassey (1999) emphasised the need for effective communication across initial teacher education partnerships. The trainee participants in this study struggled to teach literacy but some of the issues could have been addressed more proactively had a joint planning meeting taken place between the trainee, mentor and tutor prior to the start of the placement. Kate mentioned there had been no joint meeting between herself, the mentor and the university tutor prior to her placement. These meetings are useful in highlighting potential difficulties 
at the start of placements and identifying reasonable adjustments which can be put into place quite quickly (Riddell \& Weedon, 2006).

What was clearly evident within the data was that the mentors adopted a medical model which focused on discussing trainees' deficits rather than embracing an affirmation model of disability (French \& Swain, 2000). Sarah's use of language - 'those trainees'- also creates an othering effect. The trainee participants felt that they had many strengths to bring to the teaching profession. They highlighted personal traits such as their empathic and caring nature and their skills in building children's self-efficacy. In addition, they emphasised their skills in supporting children with special educational needs through effective differentiation and their ability to think laterally. Creativity was also identified as a strength. Data were consistent with previous research which has highlighted the strengths that trainees with dyslexia bring to the teaching profession (Chih Hoong et al. 2006; Duquette, 2000; Riddick, 2003). Despite the fact that the mentors also acknowledged these strengths they emphasised their weaknesses, thus indicating a focus on their deficits rather than focusing on their skills.

It would appear that we live in an 'ableist' society (Onken \& Slaten, 2000: 101) which does not tolerate weaknesses. Although the mentors emphasised the trainees' weaknesses, they had not considered how they might more effectively support their trainees in order to help them achieve to a higher level. Some of the trainee participants (Tom / James) felt that they could have achieved a higher grade if they had been given more support. The trainees talked about being criticised (Alice / James) and humiliated by mentors stepping in and 'rescuing' lessons (James) but there was no indication across the data that mentors had put strategies (reasonable adjustments) in place to enable trainees to achieve their full potential. The trainees perceived criticism as a form of discrimination which impacted detrimentally on their confidence, self-concept and self-esteem. As a result of mentor criticism some trainees experienced feelings of stress and anxiety and even questioned whether teaching was a suitable career option. For others, it made them more resilient. However, the data from the mentors also illustrate that there are complex issues at stake. Some mentors expressed concerns about trainees' weaknesses in relation to the competing demands that the mentors experienced. Some mentors emphasised that they wanted to recognise and support the strengths of the trainees, but felt responsible as gate-keepers to the profession, and were conscious of meeting the needs of the key stakeholders to which they were responsible - the children, senior leaders, parents and Ofsted. Some mentors felt torn between meeting the needs of their trainee and meeting the needs of their pupils. Although the trainees associated mentor criticism with discrimination, criticism of performance does not in itself constitute discrimination but perhaps reflects mentors' limited understanding of how to more effectively support trainees with dyslexia. Mentors commented that this was not addressed in mentor training. Criticism of trainee performance could also reflect the pressures that mentors experienced in relation to accountability.

The trainees' automatic association of criticism with discrimination also reflected a lack of understanding on the trainees' part of the function of criticism. Criticism of performance can be a powerful tool in improving teacher 
development if it is constructive (Pearson, 2012). The trainees did not appear to recognise the conflicting demands on their mentors in relation to balancing the needs of their trainee against the needs of other stakeholders. Since an important part of teacher development is to understand accountability it would appear that the university could have done more to support the trainees in understanding the competing priorities of their mentors. Woodhouse and Woodhouse (2012) emphasised the importance of trainees learning from experience to improve the quality of their own performance. Whilst some trainees were quick to criticise mentors who did not help them to improve, they also did not acknowledge explicitly their own responsibility for improving their professional development.

\subsection{Conclusion}

The medical model was the dominant model adopted by the mentors who tended to focus on trainees' weaknesses. The principles of the social and affirmative models of disability were not embedded during the placements of the trainees who participated in this study. The trainees who participated in this study had many strengths, as a result of having dyslexia, which they brought to the teaching profession. However, it would seem that they did not experience a positive affirmation of their disability. This led to trainees feeling unsupported, undervalued and feeling that they were detrimental to the profession. This is consistent with previous research (Griffiths, 2012). The data indicate that the role of a mentor as a teacher of teachers, i.e. as a coach, had not been understood by the mentors who participated in this study. This is an important skill in mentoring (Carter, 2015). There was no evidence that mentors had provided explicit coaching to trainees to help them develop their subject knowledge, memory and organisation and there was no evidence that trainees' strengths were harnessed so as to develop their confidence. Until the principles of the affirmative model of disability are fully embedded into schools and applied equally to all members of the school community then schools cannot develop inclusive cultures. Additionally, there was no evidence across the data that reasonable adjustments had been embedded during the trainees' placements. However, whilst the trainees criticised their mentors for these issues, it was also apparent that the mentors had not been provided with adequate training by the university to enable them to understand more comprehensively the role of the mentor as a teacher of teachers. Instead, they focused on assessing the performance of their trainees and making judgements on that performance. Aspects of teacher development, such as teacher modelling and coaching, were not discussed either by trainees or by mentors. In order to develop the capacity of mentors to more effectively support the professional development of trainees, including those with disabilities, the university has a pivotal role to play. It would appear that the university had not fulfilled its obligations towards its mentors who participated in this study and consequently the blame cannot be placed solely on them.

\subsection{Recommendations}

In relation to the ICF model (WHO, 2001) the trainees demonstrated functional difficulties at the level of the body. Examples of these included difficulty with understanding phonics and difficulties with memory. Intervention was not 
made available to address the difficulties with these functions. The trainees demonstrated activity limitations in relation to teaching literacy and difficulties with administration. For some, their participation was restricted through mentors preventing them from teaching specific curriculum areas. The attitudes of mentors and the wider policy context (i.e. the curriculum and assessment structures that they had to work within) constituted environmental barriers to trainees' participation and achievement and training for mentors did not address these issues. For some, personal strengths, such as creativity and differentiation, acted as facilitators rather than barriers to achievement, although their strengths were not used to address their difficulties.

If initial teacher education partnerships start to recognise the multi-dimensional nature of disability and the interaction between the biological and contextual factors which affect the experiences of individuals with disabilities, interventions can then be applied to address each of these factors. Partnerships could then use the ICF model to plan reasonable adjustments that specifically target different aspects of this framework. Schools and universities should work collaboratively to plan reasonable adjustments to placements prior to trainees commencing periods of school-based training and trainees should be included in this process so that their perspectives are taken in to account.

\section{References}

Barber, M. \& Mourshed, M. (2007). How the world's best performing school systems come out on top, http://mckinseyonsociety.com/downloads/reports/Education/Worlds_School Systems_Final.pdf [accessed 6.8.16]

Barnes, C. (1991). Disabled people in Britain and discrimination: A case for anti-discrimination legislation. London: Hurst and Co.

Bassey, M. (1999). Case study research in educational settings. Buckingham: Open University Press.

Beverton, S., Riddick, B., Dingley, E., English, E. \& Gallannaugh, F. (2008). Strategies for recruiting people with disabilities into initial teacher training. research report to the training development agency for schools. Durham: Durham University.

Brooks, G. (2007). What works for pupils with literacy difficulties? The effectiveness of intervention schemes (3rd ed.). London: Department for Children, Schools and Families. Available from:

http://publications.education.gov.uk/default.aspx?PageFunction=downloadop tions\&PageMode=publications\&ProductId=DCSF-00688-2007\& [accessed 7.8.16].

Burns, R. (1982). Self-Concept Development and Education. London: Holt, Rinehart and Winston.

Burns, E., \& Bell, S. (2010). Voices of teachers with dyslexia in Finnish and English further and higher education settings. Teachers and Teaching: Theory and Practice, 16, (5), 529-43.

Burns, E., \& Bell, S. (2011). Narrative constructions of professional teacher identity of teachers with dyslexia. Teachers and Teaching: Theory and Practice, 27, 592-60. https://doi.org/10.1016/j.tate.2011.03.007

Burrell, G. \& Morgan, G. (1979). Sociological paradigms and organisational analysis. London: Heinemann Educational Books. 
Cameron, H., \& Nunkoosing, K. (2012). Lecturer perspectives on dyslexia and dyslexic students within one faculty at one university in England. Teaching in Higher Education, 17, (3), 341-352. https:// doi.org/10.1080/13562517.2011.641002

Carroll, J.M., \& Snowling, M.J. (2004). Language and phonological skills in children at high risk of reading difficulties. Journal of Child Psychology and Psychiatry, 45(3), 631-40. https://doi.org/10.1111/j.1469-7610.2004.00252.x

Carter, A. (2015). Carter review of initial teacher training (ITT). London: Department for Education.

Chih Hoong, S., Kreel, M., Johnston, C., Thomas, A. \& Fong, J. (2006). Background to the disability rights commission's formal investigation into fitness standards in social work, nursing and teaching. Journal of Research in Special Educational Needs, $12,54-65$

Clough, P. \& Nutbrown, C. (2002), A student's guide to methodology. London: Sage.

Cohen, L., Manion, L., \& Morrison, K. (2000). Research methods in education (5 $5^{\text {th }}$ ed), London: Routledge Falmer.

Denzin, N.K. (1997). Interpretive ethnography: ethnographic practice for the $21^{\text {st }}$ century, London: Sage.

Department for Education (DFE) (2010), The Importance of Teaching: The Schools White Paper, DFE.

Dewsbury, G., Clarke, K., Randall, D., Rouncefield, M., \& Sommerville, I. (2004). The anti-social model of disability. Disability and Society, 19(2), 145-158. https:// doi.org/10.1080/0968759042000181776

Department for Education. (2011). Teachers' standards. London: Department for Education.

Department for Education. (2016). Educational excellence everywhere. London: Department for Education.

Diener, E., \& Crandall, R. (1978). Ethics in social and behavioural research. Chicago: University of Chicago Press.

Doyle, W. (1997). Heard any good stories lately? A critique of the critics of narrative in educational research. Teaching and Teacher Education, 13(1), 93-99. https://doi.org/10.1016/s0742-051x(96)00039-x

Clarke, P.J. (2011). Practitioner review: reading disorders - what are effective interventions and how should they be implemented and evaluated? Journal of Child Psychology and Psychiatry, 52, 3-12. https://doi.org/10.1111/j.14697610.2010.02310.x

Duquette, C. (2000). Examining autobiographical influences on student teachers with disabilities. Teachers and Teaching: Theory and Practice, 6 (2), 215-28. https://doi.org/10.1080/713698718

Edwards, J. (1994). The scars of dyslexia: eight case studies in emotional reactions. London: Cassell.

Ferri, B. A., Hendrick Keefe, C. \& Gregg, N. (2001). Teachers with learning disabilities: a view from both sides of the desk. Journal of Learning Disabilities, 34(1), 22-32.

Fielding, N.G., \& Fielding, J.L. (1986). Linking Data, Beverly Hills CA: Sage Publications.

Frankfort-Nachmias, C., and Nachmias, D., (1992), Research Methods in the Social Sciences, London: Edward Arnold.

Fuller, M., Georgeson, J., Healey, M., Hurst, A., Kelly, K., Riddell, S., Roberts, H. \& Weedon, E. (2009). Improving disabled students' learning. experiences and outcomes. London: Routledge.

Glazzard, J. (2010), The impact of dyslexia on pupils' self-esteem, Support for learning, 25, (2), 63-69. https://doi.org/10.1111/j.1467-9604.2010.01442.x

Glazzard, J., and Dale, K. (2013), Trainee teachers with dyslexia: personal narratives of resilience, Journal of Research in Special Educational Needs, 13, (1), 26-37. https://doi.org/10.1111/j.1471-3802.2012.01254.x 
Gordon, W., \& Langmaid, R. (1988). Qualitative market research. Aldershot: Gower.

Griffiths, S. (2012). Being dyslexic doesn't make me less of a teacher: school placement experiences of student teachers with dyslexia: strengths, challenges and a model for support. Journal of Research in Special Educational Needs, 12(2), 54-65. https://doi.org/10.1111/j.1471-3802.2011.01201.x

Guba, E. G., \& Lincoln, Y.S. (2005). Paradigmatic controversies, contradictions and emerging confluences. In N.K. Denzin and Y.S. Lincoln (Eds.), The Handbook of Qualitative Research, (3rd ed), London: Sage, pp. 191-216.

Gurney P.W. (1988). Self-esteem in children with special educational needs. Routledge: London.

Habermas, J. (1972). Knowledge and Human Interests, (Trans. J. Shapiro), London: Heinemann.

Hanafin, J., Shevlin, M., Kenny, M., \& Neela, E.M. (2007). Including young people with disabilities: assessment challenges in higher education. Higher Education, 54(3), 435-48. https:/ / doi.org/10.1007/s10734-006-9005-9

Hatcher, J., Snowling, M. J. \& Griffiths, Y. M. (2002). Cognitive assessment of dyslexic students in higher education. British Journal of Educational Psychology, 72, 119-33.

Hitchcock, G. \& Hughes, D. (1989). Research and the teacher. London: Routledge.

HM Government (2010). Equality Act. London: HMSO.

Hobson, A. \& Malderez, A. (2013). Judgementoring and other threats to realizing the potential of school-based mentoring in teacher education. International Journal of Mentoring and Coaching in Education, 2 (2), 89-108. https://doi.org/10.1108/ijmce-03-2013-0019

Humphrey, N. (2002). Teacher and pupil ratings of self-esteem in developmental dyslexia. British Journal of Special Education, 29(1), 29-36. https:// doi.org/10.1111/1467-8527.00234

Humphrey, N. (2003). Facilitating a positive sense of self in pupils with dyslexia: the role of teachers and peers. Support for Learning, 18(3), 130-136. https:// doi.org/10.1111/1467-9604.00295

Humphrey, N. \& Mullins, P.M. (2002a). Personal constructs and attribution for academic success and failure in dyslexia. British Journal of Special Education, 29(4), 196-203. https:// doi.org/10.1111/1467-8527.00269

Humphrey, N. \& Mullins, P.M. (2002b). Self-concept and self-esteem in developmental dyslexia. Journal of Research in Special Educational Needs, 2, (2), 1-13. https:// doi.org/10.1111/j.1471-3802.2002.00163.x

Humphrey, N. (2001). Self-Concept and Self-Esteem in Developmental Dyslexia: Implications for Teaching and Learning, Liverpool John Moores University: Unpublished PhD manuscript.

Ions, E. (1977). Against behaviouralism: A critique of behavioural science. Oxford: Basil Blackwell.

Kimmel, A. J. (1988). Ethics and values in applied social research. Beverly Hills: Sage.

Lawrence, D. (1996). Enhancing self-esteem in the classroom. London: Paul Chapman.

Lincoln, YS. \& Guba, EG. (1985). Naturalistic Inquiry. Newbury Park, CA: Sage Publications.

Madriaga, M. (2007). Enduring disablism: students with dyslexia and their pathways into UK higher education and beyond. Disability and Society, 22(4), 399-412. https://doi.org/10.1080/09687590701337942

Madriz E. I. (1998). Using focus groups with lower socio-economic status Latina women. Qualitative Inquiry, 24(1) 114-28. https:/ / doi.org/10.1177/107780049800400107

Mc.Donald, W.J. (1993). Focus group research dynamics and reporting: an examination of research objectives and moderator influences. Journal of the Academy of Marketing Science, 12, 161-8. https:// doi.org/10.1007/bf02894427 
McCracken, G. (1988). The long interview: Qualitative research methods series No.13, Newbury Park, CA; Sage.

McLoughlin, D., Leather, C. \& Stringer, P. (2002). The adult dyslexic. interventions and outcomes. London: Whurr.

Merton R. K., Fiske, M., \& Kendall P. L. (1956). The Focused Interview Glencoe IL: Free Press.

Morgan, E. \& Burn, E. (2000). Three perspectives on supporting a dyslexic trainee teacher. Innovations in Education and Training International, 37(2), 172-7. https://doi.org/10.1080/13558000050034538

Mortimore, T. \& Crozier, W. R. (2009). Dyslexia and difficulties with study skills in higher education. Studies in Higher Education, 31(2), 235-51. https:// doi.org/10.1080/03075070600572173

Nutbrown, C. (1999). Focused conversations in research. Sheffield: University of Sheffield, School of Education.

Oliver, M. (1990). The politics of disablement, Basingstoke: Macmillan.

Oliver, M. (1996). Understanding disability, Basingstoke: Macmillan

Onken, S. \& Slaten, E. (2000). Disability identity formation and affirmation: the experiences of persons with severe mental illness. Sociological Practice: A Journal of Clinical and Applied Sociology, 2(2), 99-111.

Patton, M.Q. (1980). Qualitative evaluation and research methods. Newbury Park, CA: Sage.

Pavey, B., Meehan, M. \& Waugh, A. (2010). Dyslexia-friendly further and higher education. London: Sage.

Pearson, L.A. (2012). 'Developing through mentoring and reflection'. In N. Denby (Ed). Training to teach: a guide for students. 73-87.

Peterson, C., Maier, S. F. \& Seligman, M. E. P. (1995). Learned helplessness: a theory for the age of personal control. Oxford: Oxford University Press.

Polkinghorne, D.E. (2007). Validity issues in narrative research. Qualitative Inquiry, 13(4), 471-486. https:/ / doi.org/10.1177/1077800406297670

Pollak, D. (Ed.) (2009). Neurodiversity in higher education: positive responses to specific learning differences. Chichester: Wiley.

Riddell, S. \& Weedon, E. (2006). What counts as a reasonable adjustment? Dyslexic students and the concept of fair assessment. International Studies in Sociology of Education, 16(1), 57-73. https:/ / doi.org/10.1080/19620210600804301

Riddick, B. \& English, E. (2006). Meeting the standards? Dyslexic students and the selection process for initial teacher training. European Journal of Teacher Education, 29(2), 203-22. https:/ / doi.org/10.1080/02619760600617383

Riddick, B. (2000). An examination of the relationship between labelling and stigmatisation with special reference to dyslexia. Disability and Society, 15(4), 653-67. https://doi.org/10.1080/09687590050058233

Riddick, B. (2001). Dyslexia and inclusion: time for a social model of disability perspective? International Studies in Sociology of Education, 11(3), 223-36. https://doi.org/10.1080/09620210100200078

Riddick, B. (2003). Experiences of teachers and trainee teachers who are dyslexic. International Journal of Inclusive Education, 7(4), 389-402. https://doi.org/10.1080/1360311032000110945

Roaf, C., \& Bines, H. (1989). Needs, rights and opportunities in special education. In C.

Roaf and H. Bines (Eds.), Needs, rights and opportunities: developing approaches to special education, London: Falmer, 321-328.

Rose, J. (2006). Independent review of the teaching of early reading: final report. Nottingham: Department for Education and Skills.

Rose, J. (2009). Identifying and teaching children and young people with dyslexia and literacy difficulties, Nottingham: DCSF. DCSF-00659-2009.

Silverman, D. (1993). Interpreting qualitative data. London: Sage. 
Silverman, D. (2010). Doing qualitative research (3 $3^{\text {rd }}$ ed). London: Sage.

Skidmore, D. (2004). Inclusion: the dynamic of school development. Berkshire: Open University Press.

Smith J. A., Flowers, P. \& Osborn, M. (1997). Interpretative phenomenological analysis and the psychology of health and illness. In L. Yardley (Ed.), Material discourses in health and illness, (pp. 68-91). London: Routledge.

Snowling, M. (1995). Phonological processing and developmental dyslexia. Journal of Research in Reading, 18, 132-138.

Snowling, M. (1998). Dyslexia as a phonological deficit: evidence and implications. Child Psychology and Psychiatry Review, 3(1), 4-11. https://doi.org/10.1017/s1360641797001366

Snowling, M.J. \& Hulme, C. (2011). Evidence-based interventions for reading and language difficulties: creating a virtuous circle. British Journal of Educational Psychology, 81, 1-23. https://doi.org/10.1111/j.2044-8279.2010.02014.x

Snowling, M.J. \& Hulme, C. (2012). Interventions for children's language and literacy difficulties. International Journal Language \& Communication Disorders, 47(1), 2734. doi: 10.1111/ j.1460-6984.2011.00081.x

Snowling, M. J. (2013). Early identification and intervention for dyslexia: a contemporary view. Journal of Research in Special Educational Needs, 13(1), 7-14. https://doi.org/10.1111/j.1471-3802.2012.01262.x

Stewart, D. \& Shamdasani, P.N. (1990), Focus groups: theory and practice. Applied Social Research Methods Series, (20). London: Sage.

Swain, J. \& French, S. (2000). Towards an affirmation model of disability. Disability \& Society, 15(4), 569-82. https://doi.org/10.1080/09687590050058189

Swain, J., \& French, S. (2003). Towards an affirmation model of disability. In M. Nind, J. Rix, K. Sheehy and K. Simmons (Eds.), Inclusive education: diverse perspectives, (pp.150-164). London: David Fulton.

Thomas, G., \& Loxley, A. (2001). Deconstructing special education and constructing inclusion. Berkshire: Open University Press.

Thomas, G., \& Loxley, A., (2007). Deconstructing special education and constructing inclusion. ( $2^{\text {nd }}$ edn). Berkshire: Open University Press.

Timmerman, G. (2009). Teacher educators modeling their teachers? European Journal of Teacher Education, 32(3), 225-38.

Tregaskis, C. (2002). Social model theory: the story so far ... Disability and Society, 17(4), 457-470. https:// doi.org/10.1080/09687590220140377

Ulmenstein, C. von. (1995). Beyond demographics: Qualitative breakthroughs in South Africa. In K. Ruyter. (1996), 'Focus versus nominal group interviews: A comparative analysis', Marketing, Intelligence and Planning, 14, (6), 44-50. https://doi.org/10.1108/02634509610131153

Velluntino, F. R., Fletcher, J. M., Snowling, M. J. \& Scanlon, D. M. (2004). Specific reading disability (dyslexia): what have we learned in the past four decades? Journal of Child Psychology and Psychiatry, 45(1), 2-20. https://doi.org/10.1046/j.00219630.2003.00305.x

Wilkinson, S., (2004). Focus Group Research. In D. Silverman (Ed.), Qualitative research: theory, method and practice. London: Sage.

Woodhouse, F. \& Woodhouse, M. 'Professionalism, the professional duties of teachers and legal requirements'. In In N. Denby (Ed). Training to teach: a guide for students. 26-40.

World Health Organisation (2001). Towards a Common Language for Functioning, Disability and Health. Geneva: The International Classification of Functioning, Disability and Health. World Health Organisation. 